\title{
Challenges in the Diagnosis and Treatment of Homozygous Familial Hypercholesterolemia
}

\author{
Matthew K. Ito ${ }^{1}$ Gerald F. Watts ${ }^{2}$
}

Published online: 14 September 2015

(c) The Author(s) 2015. This article is published with open access at Springerlink.com

\begin{abstract}
Homozygous familial hypercholesterolemia $(\mathrm{HoFH})$ is a rare, genetic disorder characterized by an absence or impairment of low-density lipoprotein receptor (LDLR) function resulting in significantly elevated lowdensity lipoprotein cholesterol (LDL-C) levels. The cholesterol exposure burden beginning in utero greatly increases the risk for atherosclerotic cardiovascular disease (ASCVD) and premature death. The genetic heterogeneity of HoFH results in a wide range of LDL-C levels among both untreated and treated patients. Diagnosis of $\mathrm{HoFH}$ should, therefore, be based on a comprehensive evaluation of clinical criteria and not exclusively LDL-C levels. As treatment goals, the European Atherosclerosis Society and International FH Foundation suggest target LDL-C levels of $<100 \mathrm{mg} / \mathrm{dL}(<2.5 \mathrm{mmol} / \mathrm{L})$ in adults or $<70 \mathrm{mg} / \mathrm{dL}$ $(<1.8 \mathrm{mmol} / \mathrm{L})$ in adults with clinical coronary artery disease or diabetes. The National Lipid Association (NLA) recommends that LDL-C levels be reduced to $<100 \mathrm{mg} / \mathrm{dL}$ $(<2.5 \mathrm{mmol} / \mathrm{L})$ or by at least $\geq 50 \%$ from pretreatment levels. Conventional therapy combinations that lower atherogenic lipoproteins levels in the blood, such as statins, ezetimibe, bile acid sequestrants and niacin, as well as lipoprotein apheresis, are usually unable to reduce LDL-C levels to recommended targets. Two recently approved agents that reduce lipoprotein synthesis and secretion by
\end{abstract}

Matthew K. Ito

itom@ohsu.edu

1 Oregon Health and Science University College of Pharmacy, Oregon State University, 2730 SW Moody Ave., CL5CP, Portland, OR 97201-5042, USA

2 Lipid Disorders Clinic, Cardiovascular Medicine, Royal Perth Hospital, School of Medicine and Pharmacology, University of Western Australia, Crawley, Australia the liver are lomitapide, a microsomal triglyceride transfer protein inhibitor, and mipomersen, an apolipoprotein B antisense oligonucleotide. The newly approved inhibitor of proprotein convertase subtilisin/kexin type 9 (PCSK9), evolocumab, also shows promise for the management of FH. Because of the extremely high risk for ASCVD, HoFH patients should be identified early.

\section{Key Points}

HoFH is characterized by significantly elevated LDL-C levels, which greatly increase the risk for atherosclerotic cardiovascular disease and premature death in untreated patients.

Conventional lipid-lowering therapy options, and combinations of these agents, usually cannot adequately reduce LDL-C levels in patients with HoFH.

The recently approved agents lomitapide and mipomersen as well as the inhibitor of proprotein convertase subtilisin/kexin type 9 (PCSK9), evolocumab, shows promise for HoFH management.

\section{Introduction}

Familial hypercholesterolemia (FH) is an autosomal codominant disorder of lipoprotein metabolism that is characterized by abnormally high levels of serum low-density lipoprotein cholesterol (LDL-C) and apolipoprotein B (apoB) containing lipoproteins [1-4]. Consequently, patients with FH are at an increased risk for cardiac events and early death from 
premature atherosclerotic cardiovascular disease (ASCVD). Despite the substantial socioeconomic burden of cardiovascular disease in these patients, FH continues to be severely underdiagnosed and undertreated $[2,4,5]$.

FH is caused by mutations in the LDL receptor $(L D L R)$ gene or other genes that affect LDLR function [1-3]. Patients with heterozygous $\mathrm{FH}(\mathrm{HeFH})$ carry a single inherited copy of the mutant gene and have cholesterol levels that are 2- to 3-fold higher than normal [2, 3, 6, 7]. Homozygous $\mathrm{FH}(\mathrm{HoFH})$, the more aggressive and rare form of FH, results from two inherited mutant alleles of the defective gene resulting in cholesterol levels that are 3- to 6-fold higher than normal [3].

HoFH is characterized by an absence or impairment in LDLR itself or in pathways that regulate the uptake of LDL-C [6, 7]. The physical signs of HoFH are generally more severe and occur at an earlier age than in patients with $\mathrm{HeFH}[1,3,6,7]$, and untreated patients with $\mathrm{HoFH}$ generally present with atherosclerosis, aortic valve disease, and coronary heart disease before the age of 20 years [2, 5, 8]. The life-long exposure to profound hypercholesterolemia is directly responsible for vascular endothelial damage and accelerated atherosclerosis, greatly increasing the risk for premature coronary artery disease (CAD), peripheral artery disease, and valvular disease, especially aortic stenosis [5, 7]. The deposition of cholesterol in vascular and extravascular compartments, such as tendons and skin, results in xanthomas (Fig. 1) and the deposition of lipid in the cornea of the eyes causes corneal arcus and an increase in intraocular pressure [1]. Patients should be identified early and provided aggressive interventions to reduce the cumulative LDL-C burden $[2,5]$.

\section{Prevalence of Homozygous Familial Hypercholesterolemia}

According to historical estimates, the worldwide prevalence of HoFH is 1:1 million [6,9]. These estimates were calculated as an extrapolation of a 1973 study of a small cohort of survivors of myocardial infarction, which estimated the prevalence of $\mathrm{HeFH}$ as 1 case per 300-500 people [10]. More recent studies based on the direct screening of an unselected population in Northern Europe showed a prevalence of $\mathrm{HeFH}$ of 1 in 200, and by extrapolation, HoFH may affect up to 6 individuals per million (or 1 in 160,000-300,000) [5].

\section{Genetics of Familial Hypercholesterolemia}

HoFH is a disease that results from a defect in recycling cholesterol through the usual LDLR-mediated mechanisms $[11,12]$. Upon binding to apoB, the LDL ligand receptor complex undergoes receptor-mediated endocytosis (Fig. 2), thereby reducing serum LDL-C levels. Mutations in $L D L R$ that prevent apoB binding to LDLR or result in a complete absence of LDLR protein effectively result in a defective uptake of LDL-C from the circulation, and, consequently, an increase in serum LDL-C levels. More than 1700 such mutations in the $L D L R$ gene have been identified [5].

Less commonly, patients with a clinical HoFH phenotype may have mutations in the genes encoding apoB, proprotein convertase subtilisin/kexin 9 (PCSK9), or the LDLR adapter protein 1 (LDLRAP1), which lead to elevations in LDL-C [11, 12]. Mutations in apoB can inhibit binding to LDLR, thereby causing elevated LDL-C levels in the blood [13]. The PCSK9 protease binds to the LDLLDLR complex targeting it for degradation in lysosomes, thereby preventing normal recycling of LDLR back to the cell surface (Fig. 2). Gain-of-function mutations in PCSK9 are thought to constitutively target the LDL-receptor complex down a degradative pathway [14]. LDLRAP1 is an adapter protein that binds to clathrin and facilitates the endocytosis of the LDL-receptor complex (Fig. 2). Lossof-function mutations in the LDLRAPl gene prevent internalization of the LDL-LDLR complex. These recessive mutations cause a rare form of $\mathrm{FH}$ called autosomal recessive hypercholesterolemia (ARH), a condition resembling $\mathrm{HoFH}$ [15].
Fig. 1 a Interdigital and b extensor tendon xanthomata in a young patient with homozygous familial hypercholesterolemia. Images reproduced with permission from Dr. Kirk Blom of the University of Cape Town Lipid Clinic
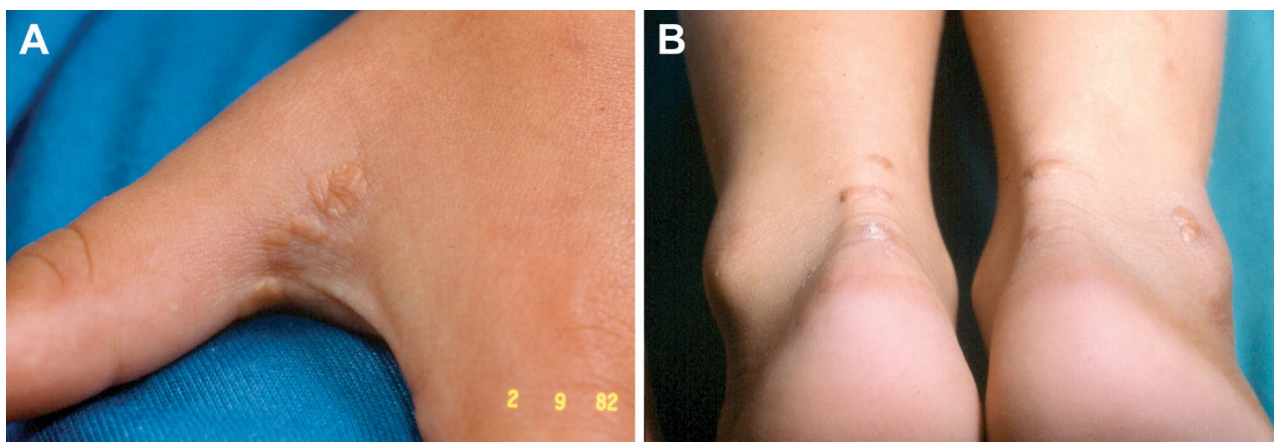
Fig. 2 Proteins involved in lipoprotein metabolism that are mutated in HoFH. ApoB apolipoprotein $\mathrm{B}, L D L$ lowdensity lipoprotein, $L D L R$ lowdensity lipoprotein receptor, LDLRAP1 low-density lipoprotein receptor associated protein 1, PCSK9 pro-protein convertase subtilisin/kexin 9
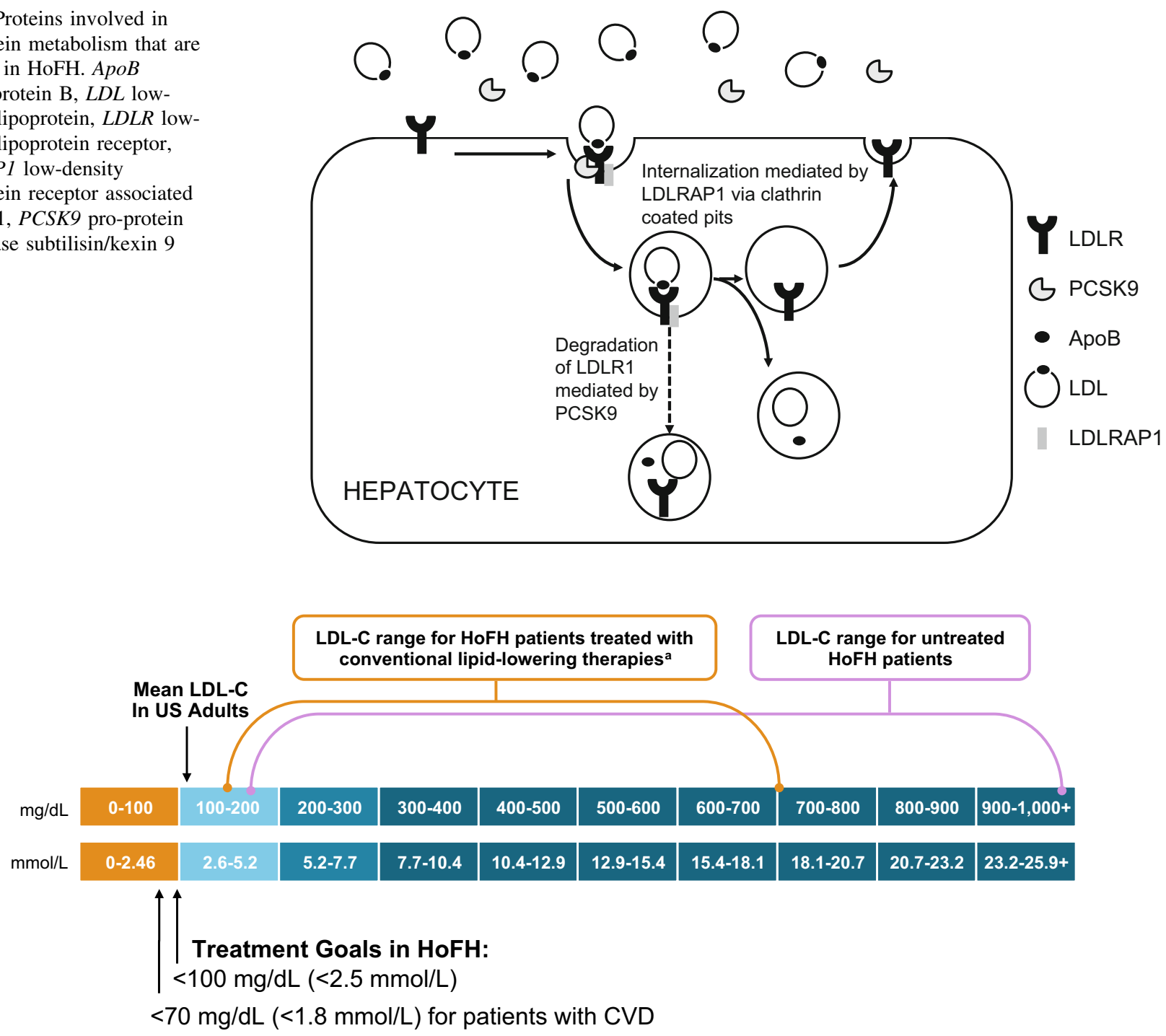

ancludes studies with statins, ezetimibe, niacin, fibrates, cholesterol absorption inhibitors, bile acid sequestrants and apheresis.

Fig. 3 Range of LDL-C levels reported in HoFH patients in published literature [6, 16-23]. $C V D$ cardiovascular disease, $L D L-C$ low-density lipoprotein cholesterol, HoFH homozygous familial hypercholesterolemia

Regardless of the mutation status, the severity of $\mathrm{HoFH}$ is based on LDL-C levels [6]. There is considerable heterogeneity in LDL-C levels among HoFH patients (Fig. 3) resulting from the large number of contributing mutations and their effects on LDL-C metabolism [6, 1623]. Whereas some mutations in the $L D L R$ gene completely eliminate LDLR function $(<2 \%$ of normal activity; receptor-negative or null mutations), others reduce function by up to $75 \%$ (2-25\% of normal activity; receptor-defective mutations) [24]. Patients with receptor-negative HoFH generally have higher levels of LDL-C, respond poorly to conventional therapy, and have more accelerated disease than patients with receptor-defective HoFH [25].

Heterogeneity at the molecular level can also result from the type of mutations on each allele. True homozygous patients have two identical mutations of the LDLR gene, whereas compound heterozygous patients (still considered $\mathrm{HoFH}$ ) have different mutations on each copy of the $L D L R$ gene. Very rarely, patients can have mutations on two different genes (double heterozygous) [24]. Regardless of the allelic variations, all of these patients would be clinically diagnosed with HoFH [26].

Other confounding factors, such as incomplete penetrance or polymorphisms in other lipid modifier genes, can also contribute to the genetic heterogeneity observed in HoFH. Because of the substantial heterogeneity in the genetics of the disease, HoFH should be diagnosed phenotypically, as is common practice in the USA [2]. 


\section{Diagnosis of Familial Hypercholesterolemia}

According to the National Lipid Association (NLA) [27], the severe hypercholesterolemia phenotype (which includes $\mathrm{HoFH}$ ) should be suspected in the following patients [9]:

- Children, adolescents, or young adults ( $<20$ years) with:

- $\quad$ LDL-C $\geq 160 \mathrm{mg} / \mathrm{dL}(\geq 4.1 \mathrm{mmol} / \mathrm{L})$.

- Non-high-density lipoprotein cholesterol (nonHDL-C) $\geq 190 \mathrm{mg} / \mathrm{dL}(\geq 4.9 \mathrm{mmol} / \mathrm{L})$.

- Adults $\geq 20$ years with:

- $\quad$ LDL-C $\geq 190 \mathrm{mg} / \mathrm{dL}(\geq 4.9 \mathrm{mmol} / \mathrm{L})$.

- Non-HDL-C $\geq 220 \mathrm{mg} / \mathrm{dL}(5.7 \mathrm{mmol} / \mathrm{L})$.

Historically, the diagnosis of $\mathrm{HoFH}$ was based on untreated LDL-C levels of $>500 \mathrm{mg} / \mathrm{dL}(>12.9 \mathrm{mmol} / \mathrm{L})$ and treated levels $\geq 300 \mathrm{mg} / \mathrm{dL}(\geq 7.7 \mathrm{mmol} / \mathrm{L})$; in addition, cutaneous or tendon xanthomas before age 10 and elevated LDL-C in both parents (suggesting $\mathrm{HeFH}$ ) were also considered [7]. However, recently published data have confirmed that LDL-C levels can overlap between patients with $\mathrm{HeFH}$ and HoFH (Fig. 3) [6]. In two recent studies, patients with genetically confirmed HoFH had untreated LDL-C levels $<500 \mathrm{mg} / \mathrm{dL}(<12.9 \mathrm{mmol} / \mathrm{L}) \quad[16,28]$. Furthermore, with the use of traditional lipid-lowering agents, treated LDL-C levels of $<300 \mathrm{mg} / \mathrm{dL}(<7.7 \mathrm{mmol} /$ L) in patients with genetically confirmed HoFH have also been reported [17, 21]. Thus, diagnosis of $\mathrm{HoFH}$ should not be excluded based on treated LDL-C levels $<300 \mathrm{mg} / \mathrm{dL}$ $(<7.7 \mathrm{mmol} / \mathrm{L}$ ), but must also include other supportive clinical or genetic evidence. In the absence of a clear-cut definition of $\mathrm{HoFH}$, physicians must make a considered clinical diagnosis based on LDL-C levels and family history, as well as severity of ASCVD and response to prior treatments [26].

Genetic testing, although accurate in making a definitive diagnosis of $\mathrm{HoFH}$, is not routinely used in clinical practice, because of limited access to laboratories where these tests are conducted [6]. Furthermore, a negative genetic test may not be sufficient to prove absence of disease because the test may miss a disease-causing mutation. Genetic mutations that are identified in a patient may, however, be used to facilitate cascade screening [4, 6, 29]. Because $\mathrm{HoFH}$ is a genetic disease, there is a high likelihood of the disease being expressed within family members and three of four first-degree relatives of patients with HoFH likely have either HeFH or HoFH [30]. Physicians should screen immediate family members of the proband for risk of $\mathrm{FH}$ by testing with a plasma lipid profile with or without genetic analysis for the family mutations $[4,6]$. If another patient with $\mathrm{FH}$ is identified, first-degree relatives of that proband should also be screened. The goal of cascade testing is to reduce morbidity and mortality from ASCVD by identifying patients early and effectively managing the condition [4].

All patients diagnosed with HoFH should be assessed for other risk factors for CAD, as well as the presence of symptomatic or subclinical atherosclerosis. An assessment of cholesterol-life years, or cumulative cholesterol burden, may also be useful in risk assessment [4].

\section{Treatment Options for Homozygous Familial Hypercholesterolemia}

\subsection{Treatment Goals}

There is limited evidence from patients with $\mathrm{HoFH}$ to allow the determination of optimal post-treatment LDL-C levels. It is also unclear whether goals based on other highrisk populations, such as patients with $\mathrm{FH}$, are relevant to the HoFH population, who show massive perturbations in LDL-C metabolism. In the absence of such clinical evidence, LDL-C targets comparable to those in the normolipidemic population are ideal, but in reality a $50 \%$ reduction in LDL-C levels is the best that can be achieved and is a good starting point until further evidence accrues.

Several evidence-based guidelines, chiefly based on expert opinion, have defined treatment goals for patients with HoFH. The European Atherosclerosis Society (EAS) has made $\mathrm{HoFH}$-specific recommendations for target LDLC levels of $<100 \mathrm{mg} / \mathrm{dL}(<2.5 \mathrm{mmol} / \mathrm{L})$ in adults or $<70 \mathrm{mg} / \mathrm{dL}(<1.8 \mathrm{mmol} / \mathrm{L})$ in adults with clinical coronary heart disease $(\mathrm{CHD})$ or diabetes $[5,6]$. The EAS acknowledges, however, that "such targets are ambitious and careful evaluation of the benefit vs. risk of therapeutic options is needed." The panel also notes that because of the phenotypic and genotypic variations associated with $\mathrm{HoFH}$, patients may respond differently to lipid-lowering therapies [6].

Evidence-based guidelines for FH from the NLA recommend that treatment goals should focus on reducing LDL-C levels by $\geq 50 \%$ from pretreatment levels if target LDL-C levels cannot be achieved [27, 31]. For high-risk patients (including $\mathrm{HoFH}$ patients), the NLA suggests that non-HDL-C and LDL-C levels be lowered to $<130 \mathrm{mg} / \mathrm{dL}$ $(<3.4 \mathrm{mmol} / \mathrm{L})$ and $<100 \mathrm{mg} / \mathrm{dL}(<2.5 \mathrm{mmol} / \mathrm{L})$, respectively. For FH patients with multiple or other poorly controlled risk factors for cardiovascular disease, the NLA recommends attaining even lower levels of atherogenic cholesterol [27].

The International FH Foundation recommends that as an initial goal, therapy should aim for a reduction of $\geq 50 \%$ in 
plasma LDL-C levels. In the absence of CHD or other major risk factors, an LDL-C treatment goal of $<100 \mathrm{mg} /$ $\mathrm{dL}(<2.5 \mathrm{mmol} / \mathrm{L})$ is recommended, whereas a goal of $<70 \mathrm{mg} / \mathrm{dL}(<1.8 \mathrm{mmol} / \mathrm{L})$ is suggested for patients with CHD or other major risk factors [4].

\subsection{Lifestyle Modifications}

Patients should be counseled to consume a heart-healthy diet low in saturated fat and cholesterol and encouraged to participate in appropriate levels of physical activity. Patients should aggressively control other traditional risk factors, such as smoking, hypertension, diabetes, and obesity. Despite these lifestyle modifications, pharmacologic intervention is generally required to reduce nonHDL-C and LDL-C levels in patients with HoFH [6].

\subsection{Conventional Therapies}

Several classical treatment options are available for lowering lipid levels in patients with HoFH (Table 1). Statins, the mainstay of therapy, lower LDL-C levels predominantly by upregulating LDLR. Because patients with HoFH lack fully functioning LDLR, statins are not generally effective in this population, in whom only modest reductions in LDL-C levels of $\sim 20 \%$ are observed [32, 33]. The addition of ezetimibe, an inhibitor of cholesterol absorption, to statins may further lower LDL-C levels by $10-15 \%$ with minimal adverse events while also reducing the incidence of cardiovascular events [18, 34]. Combining statins with other drugs, such as bile acid sequestrants or niacin may also lower LDL-C levels, but the use of these combinations may be limited by adverse events [6]. Patients with $\mathrm{HoFH}$ are frequently refractory to these conventional lipid-lowering therapies, which rarely lower LDL-C levels in these patients to the recommended target goals [6].

Lipoprotein apheresis (LA) is a treatment option available to some patients with $\mathrm{HoFH}$ who cannot tolerate drug therapy or in whom the drugs are ineffective. A single treatment can effectively reduce serum LDL-C levels by between 50 and $70 \%$. Although LA is repeated every 1 to 2 weeks, LDL-C levels are not consistently maintained within acceptable limits. LDL-C levels rebound rapidly after treatment returning to 50 and $90 \%$ of pre-apheresis levels after 4 and 14 days, respectively [35]. Long-term use of LA has been reported to promote regression of xanthomas, slow the progression of atherosclerosis, and mediate a marked reduction in the inflammation of arterial walls that is characteristic of FH $[31,36]$. Although LA is time consuming and not easily available to all $\mathrm{HoFH}$ patients, it may be a cost-effective option for the treatment of HoFH [4].

Liver transplantation (alone or in combination with a heart transplant) may be considered for young HoFH patients, although disadvantages for this approach include the high risk of post-transplantation complications and mortality, as well as the limited availability of donors.

Table 1 Mechanisms of actions of lipid-lowering therapies

\begin{tabular}{|c|c|c|}
\hline Lipid-lowering therapy & Mechanism of action & LDL-lowering response in patients with $\mathrm{HoFH}$ \\
\hline \multicolumn{3}{|l|}{ Conventional therapies } \\
\hline Statins & $\begin{array}{l}\text { Competitively inhibit HMG CoA reductase reducing } \\
\text { endogenous cholesterol synthesis (LDLR up-regulator) }\end{array}$ & Up to $28 \%$ \\
\hline Ezetimibe & Inhibits cholesterol absorption & $<10 \%$ \\
\hline Bile acid sequestrants & $\begin{array}{l}\text { Decrease reabsorption of bile acids and reduce } \\
\text { cholesterol content in hepatocytes }\end{array}$ & $<10 \%$ \\
\hline Niacin & Decrease VLDL synthesis & $<10 \%$ \\
\hline LDL apheresis & $\begin{array}{l}\text { Removes LDL particles from the circulation using } \\
\text { dextran sulphate or heparin }\end{array}$ & $20-40 \%$ \\
\hline \multicolumn{3}{|l|}{ Novel treatment options } \\
\hline Lomitapide & $\begin{array}{l}\text { Inhibits microsomal triglyceride transfer protein, thereby } \\
\text { interfering with the assembly of lipoproteins }\end{array}$ & $\begin{array}{l}50 \% \text { (in combination with conventional therapies } \\
\text { including LDL apheresis) [17] }\end{array}$ \\
\hline Mipomersen & Inhibits apoB synthesis & $\begin{array}{l}25 \% \text { (in combination with conventional therapies } \\
\text { excluding LDL apheresis) [21] }\end{array}$ \\
\hline $\begin{array}{l}\text { PCSK9 inhibitors } \\
\text { (evolocumab, alirocumab, } \\
\text { bococizumab) }\end{array}$ & $\begin{array}{l}\text { Inhibits PCSK9, which regulates recycling of the LDLR } \\
\text { (LDLR up-regulator) }\end{array}$ & $\begin{array}{l}23 \% \text { (for evolocumab in combination with } \\
\text { conventional therapies excluding LDL apheresis) } \\
\text { [49] }\end{array}$ \\
\hline
\end{tabular}

HDL high-density lipoprotein, $L D L$ low-density lipoprotein, $L D L R$ low-density lipoprotein receptor, PCSK9 pro-protein convertase subtilisin/ kexin 9, PPAR $\alpha$ peroxisome proliferator-activated receptor-alpha, $V L D L$ very-low-density lipoprotein 
Other options, such as partial ileal bypass and portocaval shunting, are not recommended for this population but may be considered for patients with very severe disease in whom other conventional options are not effective $[4,6]$.

\subsection{Other Treatment Options}

The EAS has suggested a treatment algorithm showing how lifestyle modifications can be combined with conventional pharmacotherapy for the management of HoFH (Fig. 4) [6]. Despite the availability and use of the conventional pharmacotherapy, only a small proportion of patients with $\mathrm{HoFH}$ achieve the non-HDL-C and LDL-C targets recommended by the NLA guidelines [27], underscoring the need for novel treatment options that decrease atherogenic cholesterol levels beyond those currently achieved. Lomitapide and mipomersen are approved as adjunct therapy to conventional lipid-lowering therapies for $\mathrm{HoFH}$ in patients $\geq 18$ and $\geq 12$ years, respectively [37, 38]. The two drugs have not been compared directly in head-to-head studies. Both drugs have different mechanisms of action, but they effectively reduce the production and secretion of apoB-containing lipoproteins. Because of the potential risk for hepatic toxicity, both lomitapide and mipomersen are restricted for use in patients with HoFH who are participating in a Risk Evaluation and Mitigation Strategy (REMS) program [6]. Two PCSK9 inhibitors, evolocumab and alirocumab, have been recently been approved in the US, evolocumab for the treatment of $\mathrm{HoFH}$, and alirocumab for the treatment of patients with clinical atherosclerotic cardiovascular disease who require additional lowering of LDL-C $[39,40]$. Additional data on long-term safety and efficacy for these products are needed. These long-term data can also be used for detailed cost/benefit analyses of the novel products for $\mathrm{HoFH}$, whose prices are consistent with other drugs that have orphan designations [41].

\subsubsection{Lomitapide}

Lomitapide is an oral inhibitor of the microsomal triglyceride transport protein (MTP), which transfers triglycerides and phospholipids onto apoB, thereby playing an important role in the assembly and secretion of apoB-containing lipoproteins in the liver and intestines [42]. By inhibiting MTP, lomitapide induces post-translational degradation of apoB, thereby reducing the secretion of lipoproteins into

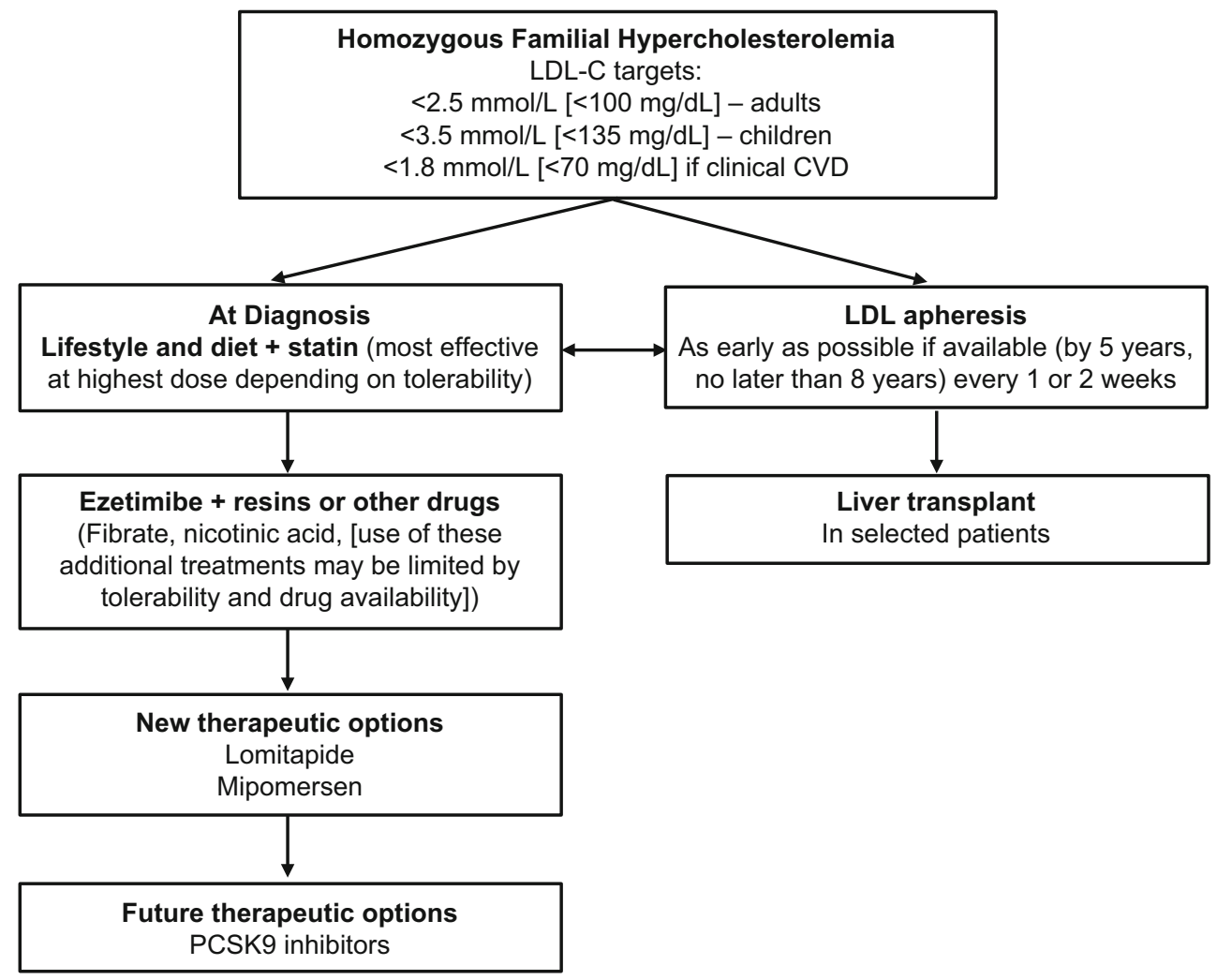

Fig. 4 Recommended algorithm for management of HoFH (adapted from Cuchel M, Homozygous familial hypercholesterolaemia: new insights and guidance for clinicians to improve detection and clinical management. A position paper from the Consensus Panel on Familial Hypercholesterolaemia of the European Atherosclerosis Society,
European Heart Journal, 2014, Volume 35, Issue 32, 2146-2157, by permission of Oxford University Press [6]). CVD cardiovascular disease, $L D L$ low-density lipoprotein, $L D L-C$ low-density lipoproteincholesterol, PCSK 9 pro-protein convertase subtilisin/kexin 9 
the blood, resulting in lower serum cholesterol and triglyceride levels $[42,43]$.

In an open-label, dose-escalation study of 29 patients with $\mathrm{HoFH}$, lomitapide (5 to $60 \mathrm{mg} /$ day) was added to standard of care including LA [17]. Of the 23 patients who completed treatment (median lomitapide dose, $40 \mathrm{mg} /$ day), mean LDL$\mathrm{C}$, apoB, and lipoprotein(a) levels were reduced by $50 \%$ $(p<0.0001), 49 \%(p<0.0001)$, and $15 \%(p=0.0003)$ at 26 weeks. Of the 18 patients on the study who underwent routine LA, three permanently discontinued the procedure and another three increased the duration between apheresis sessions. The LDL-C-lowering effect was durable, with a reduction of $44 \%(p<0.0001)$ and $38 \%(p=0.0001)$ observed at weeks 52 and 78, respectively. Similarly, apoB levels were significantly reduced by $45 \%(p<0.0001)$ and $43 \%(p<0.0001)$ at these later time points. However, the effect of lomitapide on lipoprotein(a) levels was not sustained returning to baseline at 78 weeks.

The most common adverse events reported in $93 \%$ of patients were gastrointestinal in nature [mitigated by adherence to a low-fat diet (i.e. supplying $<20 \%$ of total energy from fat)], accumulation of liver fat, and elevations in alanine aminotransaminase levels. Because the cytochrome P450 enzyme, CYP3A4, metabolizes lomitapide, there is a potential for interaction with even moderate inhibitors of the enzyme, suggesting that concomitant administration of the two drugs should be carefully considered [37]. It should be noted, however, that a phase 1 study showed no clinically relevant increase in lomitapide exposure with the weak CYP3A4 inhibitors, atorvastatin and ethinyl estradiol/norgestimate [44].

Long-term follow-up data were collected from 19 of 23 patients who completed the phase 3 trial and entered an open-label extension study [45]. Patients continued lomitapide treatment at their maximum tolerated dose and 17/19 $(89 \%)$ of patients completed at least 126 weeks of treatment at which point LDL-C levels were reduced by $45.5 \%$ compared with baseline. No new safety signals were identified during the long-term extension study.

\subsubsection{Mipomersen}

Mipomersen is an antisense oligonucleotide directed against the messenger RNA (mRNA) of apoB, the main protein component of LDL and very-low-density lipoprotein (VLDL). By inducing degradation of the apoB mRNA, mipomersen blocks the synthesis of apoB protein, thereby reducing secretion of LDL [46].

In a placebo-controlled double-blind trial in 51 patients with $\mathrm{HoFH}$, mipomersen $200 \mathrm{mg}$ administered once/week by subcutaneous injection was added to standard lipidlowering therapies (excluding lipoprotein apheresis) [21]. When compared to placebo, mean reductions of plasma
LDL-C, apoB, and lipoprotein(a) levels of $25 \%$ $(p=0.0003), 27 \%(p<0.0001)$, and $32 \%(p=0.0013)$ were observed at 26 weeks. Common adverse events with mipomersen included flu-like reactions, injection site reactions, and elevations in alanine aminotransaminase levels. Liver fat was not measured in this study, but increased liver fat content was observed in other trials of patients with hypercholesterolemia and $\mathrm{HeFH}$ [47].

A total of 141 patients treated with mipomersen in three different trials (including 38 with $\mathrm{HoFH}$ ) were enrolled in an open-label, 104-week extension study [48]. Among patients who completed 2 years of treatment, the mean change in LDL-C from baseline to week 104 was a decrease of $28 \%$. Significant reductions in ApoB and lipoprotein(a) levels of $31 \%(p<0.0001)$ and $17 \%$ $(p<0.0001)$ were also observed at this later time point. It should be noted, however, that 77/141 (55\%) of patients discontinued treatment within the first 2 years ( $43 \%$ due to treatment-emergent adverse events). No new safety signals were observed during the long-term extension study.

\subsubsection{PCSK9 Inhibitors}

PCSK9 is a protein that targets LDLR for degradation. Inhibitors of PCSK9, both monoclonal antibodies and small molecule inhibitors, are being evaluated in clinical trials of patients with FH. Evolocumab, an anti-PCSK9 monoclonal antibody, was approved in July 2015 by the European Medicines Agency for the treatment of adults and adolescents aged 12 years and over with $\mathrm{HoFH}$ in combination with other lipid-lowering therapies [39]. A second PCSK9 inhibitor, alirocumab, has also been approved in July 2015 by the US Food and Drug Administration (FDA) as an adjunct to diet and maximally tolerated statin therapy for adult patients with $\mathrm{HeFH}$ or clinical ASCVD, who need additional lowering of LDL cholesterol [40].

The safety and efficacy of evolocumab was evaluated in TESLA (Trial Evaluating PCSK9 Antibody in Subjects With LDL Receptor Abnormalities), a phase 3 randomized, double-blind trial in 49 patients with HoFH who were not on LA [49]. The patients were randomized to evolocumab $(n=33)$ or placebo $(n=16)$. Overall, evolocumab administered subcutaneously at a dose of $420 \mathrm{mg}$ every 4 weeks reduced LDL-C levels by $23.1 \%$ from baseline and $30.9 \%$ compared with the placebo arm, and lipoprotein(a) levels were reduced by $11.8 \%$ from baseline. It should be noted, however, that the mean LDL-C levels in patients treated with evolocumab were $7.1 \mathrm{mmol} / \mathrm{L}$ $(275 \mathrm{mg} / \mathrm{dL})$, suggesting that combinations of PCSK9 inhibitors with newer agents, such as lomitapide or mipomersen, have the potential to further lower LDL-C levels in patients with $\mathrm{HoFH}$. 
The response to evolocumab was dependent on LDLR status and patients with receptor-defective mutations on either one $(n=20)$ or both alleles $(n=8)$ showed a mean reduction in LDL-C levels of 40.8 and $46.9 \%$ compared with placebo. One patient with LDLR-negative mutations on both alleles and one patient with ARH did not respond to evolocumab; a slight increase in LDL-C levels compared with baseline was observed [49]. Similar results were observed in preclinical studies using human dermal fibroblasts isolated from receptor-defective $(n=9)$ and receptor-negative $(n=4)$ HoFH patients exposed to alirocumab. In cells incubated with mevastatin (to upregulate LDLR) followed by recombinant PCSK9 with or without the antibody, alirocumab restored cell surface expression of LDLR in cells from receptor-defective $\mathrm{HoFH}$ patients, whereas LDLR expression in cells from receptor-negative patients was almost undetectable [50].

The most common adverse events with evolocumab were infections of the upper respiratory tract, influenza, gastroenteritis and nasopharyngitis, which are relatively common with monoclonal antibody drugs.

\subsection{Future Options}

Several other novel options for the treatment of $\mathrm{HoFH}$, such as gene therapy, are also being investigated. Gene therapy is a strategy used to correct defective genes responsible for the development of disease. For example, replacement of the $L D L R$ gene has the potential to decrease LDL-C levels while also making patients with HoFH more responsive to conventional therapies [6]. Preclinical studies using mouse models of $\mathrm{HoFH}$ and $\mathrm{HeFH}$ have yielded promising results [51]. Additional studies and clinical trials of these gene replacement strategies are warranted.

\section{Conclusion}

$\mathrm{HoFH}$ is a rare disorder of cholesterol metabolism that is underdiagnosed and undertreated. Evidence in the published literature demonstrates that patients with $\mathrm{HoFH}$ can benefit from early diagnosis and treatment. Diagnosis should be based on a comprehensive evaluation of clinical criteria and should not be exclusively based on LDL-C levels because of the wide range of LDL-C levels observed among untreated and treated patients. This variability in LDL-C levels can be attributed, at least in part, to the genetic heterogeneity of the disease. However, the degree of LDL-C elevation can reflect the efficacy of baseline treatment and provides the best index for the need for additional and more aggressive treatment(s). While genetic testing can provide a definitive diagnosis for some $\mathrm{HoFH}$ patients, many patients may not be identified because of the high false-negative rate, as well as the absence of validated tests for all mutations that may cause the disease.

Early detection and aggressive intervention with statins in combination with other lipid-lowering agents, along with lipoprotein apheresis, is generally recommended for $\mathrm{HoFH}$ patients. However, the combination of these agents and procedures cannot usually bring LDL-C levels to the recommended treatment goals. Recently approved agents, such as lomitapide, mipomersen, and evolocumab have shown efficacy in further reducing LDL-C levels in patients with HoFH. Patients with HoFH need access to these novel non-statin agents to help control their LDL-C levels. The impact of these new treatments on cardiovascular events has not been determined and needs evaluation.

Acknowledgments Editorial assistance was provided by Supriya Srinivasan, $\mathrm{PhD}$, and Leta Shy of Scientia Medical Communications, LLC, and sponsored by Aegerion Pharmaceuticals, Inc. (Cambridge, MA). Aegerion also supported the request of permission for the reproduction of figures in this article. Aegerion had the opportunity to review this work for scientific accuracy and any changes resulting from comments received were made by the authors solely on the basis of scientific or editorial merit. The authors wrote and retained full control of the content of the paper.

Open Access This article is distributed under the terms of the Creative Commons Attribution-NonCommercial 4.0 International License (http://creativecommons.org/licenses/by-nc/4.0/), which permits any noncommercial use, distribution, and reproduction in any medium, provided you give appropriate credit to the original author(s) and the source, provide a link to the Creative Commons license, and indicate if changes were made.

\section{References}

1. Hovingh GK, Davidson MH, Kastelein JJ, O'Connor AM. Diagnosis and treatment of familial hypercholesterolaemia. Eur Heart J. 2013;34(13):962-71. doi:10.1093/eurheartj/eht015.

2. Sniderman AD, Tsimikas S, Fazio S. The severe hypercholesterolemia phenotype: clinical diagnosis, management, and emerging therapies. J Am Coll Cardiol. 2014;63(19):1935-47. doi:10.1016/j.jacc.2014.01.060.

3. Vishwanath R, Hemphill LC. Familial hypercholesterolemia and estimation of US patients eligible for low-density lipoprotein apheresis after maximally tolerated lipid-lowering therapy. J Clin Lipidol. 2014;8(1):18-28. doi:10.1016/j.jacl.2013.11.002.

4. Watts GF, Gidding S, Wierzbicki AS, Toth PP, Alonso R, Brown $\mathrm{WV}$, et al. Integrated guidance on the care of familial hypercholesterolaemia from the International $\mathrm{FH}$ Foundation. Int $\mathrm{J}$ Cardiol. 2014;171(3):309-25. doi:10.1016/j.ijcard.2013.11.025.

5. Nordestgaard BG, Chapman MJ, Humphries SE, Ginsberg HN, Masana L, Descamps OS, et al. Familial hypercholesterolaemia is underdiagnosed and undertreated in the general population: guidance for clinicians to prevent coronary heart disease: consensus statement of the European Atherosclerosis Society. Eur Heart J. 2013;34(45):3478-90. doi:10.1093/eurheartj/eht273.

6. Cuchel M, Bruckert E, Ginsberg HN, Raal FJ, Santos RD, Hegele RA, et al. Homozygous familial hypercholesterolaemia: new insights and guidance for clinicians to improve detection and 
clinical management. A position paper from the Consensus Panel on Familial Hypercholesterolaemia of the European Atherosclerosis Society. Eur Heart J. 2014;35(32):2146-57. doi:10.1093/ eurheartj/ehu274.

7. Raal FJ, Santos RD. Homozygous familial hypercholesterolemia: current perspectives on diagnosis and treatment. Atherosclerosis. 2012;223(2):262-8. doi:10.1016/j.atherosclerosis.2012.02.019.

8. Widhalm K, Binder CB, Kreissl A, Aldover-Macasaet E, Fritsch M, Kroisboeck S, et al. Sudden death in a 4-year-old boy: a nearcomplete occlusion of the coronary artery caused by an aggressive low-density lipoprotein receptor mutation (W556R) in homozygous familial hypercholesterolemia. J Pediatrics. 2011;158(1):167. doi:10.1016/j.jpeds.2010.06.027.

9. Goldberg AC, Hopkins PN, Toth PP, Ballantyne CM, Rader DJ, Robinson JG, et al. Familial hypercholesterolemia: screening, diagnosis and management of pediatric and adult patients: clinical guidance from the National Lipid Association Expert Panel on Familial Hypercholesterolemia. J Clin Lipidol. 2011;5(3):133-40. doi:10.1016/j.jacl.2011.03.001.

10. Goldstein JL, Schrott HG, Hazzard WR, Bierman EL, Motulsky AG. Hyperlipidemia in coronary heart disease. II. Genetic analysis of lipid levels in 176 families and delineation of a new inherited disorder, combined hyperlipidemia. J Clinical Invest. 1973;52(7):1544-68. doi:10.1172/JCI107332.

11. Soutar AK, Naoumova RP. Mechanisms of disease: genetic causes of familial hypercholesterolemia. Nat Clin Pract Cardiovasc Med. 2007;4(4):214-25. doi:10.1038/ncpcardio0836.

12. Hopkins PN, Toth PP, Ballantyne CM, Rader DJ, National Lipid Association Expert Panel on Familial H. Familial hypercholesterolemias: prevalence, genetics, diagnosis and screening recommendations from the National Lipid Association Expert Panel on Familial Hypercholesterolemia. J Clin Lipidol. 2011;5(3 Suppl):S9-17. doi:10.1016/j.jacl.2011.03.452.

13. Innerarity TL, Weisgraber KH, Arnold KS, Mahley RW, Krauss RM, Vega GL, et al. Familial defective apolipoprotein B-100: low density lipoproteins with abnormal receptor binding. Proc Natl Acad Sci USA. 1987;84(19):6919-23.

14. Horton JD, Cohen JC, Hobbs HH. PCSK9: a convertase that coordinates LDL catabolism. J Lipid Res. 2009;50(Suppl):S172-7. doi:10.1194/jlr.R800091-JLR200.

15. Tada H, Kawashiri MA, Ohtani R, Noguchi T, Nakanishi C, Konno $\mathrm{T}$, et al. A novel type of familial hypercholesterolemia: double heterozygous mutations in LDL receptor and LDL receptor adaptor protein 1 gene. Atherosclerosis. 2011;219(2):663-6. doi:10.1016/j.atherosclerosis.2011.08.004.

16. Sjouke B, Kusters DM, Kindt I, Besseling J, Defesche JC, Sijbrands EJ, et al. Homozygous autosomal dominant hypercholesterolaemia in the Netherlands: prevalence, genotype-phenotype relationship, and clinical outcome. Eur Heart J. 2014. doi:10. 1093/eurheartj/ehu058.

17. Cuchel M, Meagher EA, du Toit Theron H, Blom DJ, Marais AD, Hegele RA, et al. Efficacy and safety of a microsomal triglyceride transfer protein inhibitor in patients with homozygous familial hypercholesterolaemia: a single-arm, open-label, phase 3 study. Lancet. 2013;381(9860):40-6. doi:10.1016/S01406736(12)61731-0.

18. Gagne C, Gaudet D, Bruckert E, Ezetimibe Study G. Efficacy and safety of ezetimibe coadministered with atorvastatin or simvastatin in patients with homozygous familial hypercholesterolemia. Circulation. 2002;105(21):2469-75.

19. Graesdal A, Bogsrud MP, Holven KB, Nenseter MS, Narverud I, Langslet $G$, et al. Apheresis in homozygous familial hypercholesterolemia: the results of a follow-up of all Norwegian patients with homozygous familial hypercholesterolemia. J Clin Lipidol. 2012;6(4):331-9. doi:10.1016/j.jacl.2012.03.004.
20. Raal FJ, Pilcher GJ, Panz VR, van Deventer HE, Brice BC, Blom DJ, et al. Reduction in mortality in subjects with homozygous familial hypercholesterolemia associated with advances in lipidlowering therapy. Circulation. 2011;124(20):2202-7. doi:10. 1161/CIRCULATIONAHA.111.042523.

21. Raal FJ, Santos RD, Blom DJ, Marais AD, Charng MJ, Cromwell WC, et al. Mipomersen, an apolipoprotein B synthesis inhibitor, for lowering of LDL cholesterol concentrations in patients with homozygous familial hypercholesterolaemia: a randomised, double-blind, placebo-controlled trial. Lancet. 2010;375(9719):998-1006. doi:10.1016/S0140-6736(10)60284$\mathrm{X}$.

22. Stein EA, Honarpour N, Wasserman SM, Xu F, Scott R, Raal FJ Effect of the proprotein convertase subtilisin/kexin 9 monoclonal antibody, AMG 145, in homozygous familial hypercholesterolemia. Circulation. 2013;128(19):2113-20. doi:10.1161/ CIRCULATIONAHA.113.004678.

23. Writing Group M, Lloyd-Jones D, Adams RJ, Brown TM, Carnethon M, Dai S, et al. Heart disease and stroke statistics-2010 update: a report from the American Heart Association. Circulation. 2010;121(7):e46-215. doi:10.1161/CIRCULATIONAHA. 109.192667.

24. Marais AD. Familial hypercholesterolaemia. Clin Biochem Rev Aust Assoc Clin Biochem. 2004;25(1):49-68.

25. Moorjani S, Roy M, Torres A, Betard C, Gagne C, Lambert M, et al. Mutations of low-density-lipoprotein-receptor gene, variation in plasma cholesterol, and expression of coronary heart disease in homozygous familial hypercholesterolaemia. Lancet. 1993;341(8856):1303-6.

26. Baum SJ, Sijbrands EJ, Mata P, Watts GF. The doctor's dilemma: challenges in the diagnosis and care of homozygous familial hypercholesterolemia. J Clin Lipidol. 2014;8(6):542-9. doi:10. 1016/j.jacl.2014.09.005.

27. Jacobson TA, Ito MK, Maki KC, Orringer CE, Bays HE, Jones $\mathrm{PH}$, et al. National Lipid Association recommendations for patient-centered management of dyslipidemia: part 1-executive summary. J Clin Lipidol. 2014;8(5):473-88. doi:10.1016/j.jacl. 2014.07.007.

28. Bertolini S, Pisciotta L, Rabacchi C, Cefalu AB, Noto D, Fasano $\mathrm{T}$, et al. Spectrum of mutations and phenotypic expression in patients with autosomal dominant hypercholesterolemia identified in Italy. Atherosclerosis. 2013;227(2):342-8. doi:10.1016/j. atherosclerosis.2013.01.007.

29. Watts GF, Sullivan DR, Poplawski N, van Bockxmeer F, Hamilton-Craig I, Clifton PM, et al. Familial hypercholesterolaemia: a model of care for Australasia. Atheroscler Suppl. 2011;12(2):221-63. doi:10.1016/j.atherosclerosissup.2011.06. 001.

30. Ned RM, Sijbrands EJ. Cascade screening for familial hypercholesterolemia (FH). PLoS Curr. 2011;3:RRN1238. doi:10.1371/ currents.RRN1238.

31. Ito MK, McGowan MP, Moriarty PM, National Lipid Association Expert Panel on Familial H. Management of familial hypercholesterolemias in adult patients: recommendations from the National Lipid Association Expert Panel on Familial Hypercholesterolemia. J Clin Lipidol. 2011;5(3 Suppl):S38-45. doi:10. 1016/j.jacl.2011.04.001.

32. Crestor [prescribing information]. Wilmington: AstraZeneca Pharmaceuticals; 2012.

33. Lipitor [prescribing information]. New York: Pfizer, Inc; 2012.

34. Blazing MA, Giugliano RP, Delemos J, Cannon CP, Musliner T, Terkashovec AM, et al., editors. On-treatment analysis of the IMProved Reduction of Outcomes: Vytorin Efficacy International Trial (IMPROVE-IT). American Heart Association Scientific Sessions; 15-19 November 2014, Chicago; 2014. 
35. Kroon AA, van't Hof MA, Demacker PN, Stalenhoef AF. The rebound of lipoproteins after LDL-apheresis. Kinetics and estimation of mean lipoprotein levels. Atherosclerosis. 2000;152(2):519-26.

36. Thompson GR, Group H-ULAW. Recommendations for the use of LDL apheresis. Atherosclerosis. 2008;198(2):247-55. doi:10. 1016/j.atherosclerosis.2008.02.009.

37. Juxtapid [prescribing information]. Cambridge: Aegerion Pharmaceuticals, Inc.; 2013.

38. Kynamro [prescribing information]. Cambridge: Genzyme Corporation; 2013.

39. Repatha [summary of product characteristics]. Breda: Amgen, Inc.; 2015.

40. Praluent [prescribing information]. Bridgewater: Sanofi and Regeneron Pharmaceuticals, Inc.; 2015.

41. Kontoghiorghe CN, Andreou N, Constantinou K, Kontoghiorghes GJ. World health dilemmas: orphan and rare diseases, orphan drugs and orphan patients. World J Methodol. 2014;4(3):163-88. doi:10.5662/wjm.v4.i3.163.

42. Hussain MM, Rava P, Walsh M, Rana M, Iqbal J. Multiple functions of microsomal triglyceride transfer protein. Nutr Metab. 2012;9:14. doi:10.1186/1743-7075-9-14.

43. Burnett JR, Watts GF. MTP inhibition as a treatment for dyslipidaemias: time to deliver or empty promises? Expert Opin Ther Targets. 2007;11(2):181-9. doi:10.1517/14728222.11.2.181.

44. King TA, Patel G, Dutta S, Korb S, Wade JR, Foulds P, et al. Evaluation of the effects of the weak CYP3A4 inhibitors atorvastatin and ethinyl estradiol/norgestimate on lomitapide pharmacokinetics in healthy subjects. Atherosclerosis. 2015;241(1):e203.

45. Cuchel M, Bloom DJ, Averna MR, Meagher EA, du Toit Theron $\mathrm{H}$, Sirtori CR, et al., editors. Sustained LDL-C lowering and stable hepatic fat levels in patients with homozygous familial hypercholesterolemia treated with the microsomal triglyceride transfer protein inhibitor, lomitapide: results of an ongoing long- term extension study. Annual Meeting of the American Heart Association; 16-20 November 2013, Dallas.

46. Crooke ST, Geary RS. Clinical pharmacological properties of mipomersen (Kynamro), a second generation antisense inhibitor of apolipoprotein B. Br J Clin Pharmacol. 2013;76(2):269-76. doi:10.1111/j.1365-2125.2012.04469.x.

47. Stein EA, Dufour R, Gagne C, Gaudet D, East C, Donovan JM, et al. Apolipoprotein B synthesis inhibition with mipomersen in heterozygous familial hypercholesterolemia: results of a randomized, double-blind, placebo-controlled trial to assess efficacy and safety as add-on therapy in patients with coronary artery disease. Circulation. 2012;126(19):2283-92. doi:10.1161/ CIRCULATIONAHA.112.104125.

48. Santos RD, Duell PB, East C, Guyton JR, Moriarty PM, Chin W, et al. Long-term efficacy and safety of mipomersen in patients with familial hypercholesterolaemia: 2-year interim results of an open-label extension. Eur Heart J. 2015;36:566-75. doi:10.1093/ eurheartj/eht549.

49. Raal FJ, Honarpour N, Blom DJ, Hovingh GK, Xu F, Scott R, et al. Inhibition of PCSK9 with evolocumab in homozygous familial hypercholesterolaemia (TESLA Part B): a randomised, double-blind, placebo-controlled trial. Lancet. 2015;385(9965):341-50. doi:10.1016/S0140-6736(14)61374-X.

50. Lambert G, Chatelais M, Petrides F, Passard M, Thedrez A, Rye $\mathrm{KA}$, et al. Normalization of low-density lipoprotein receptor expression in receptor defective homozygous familial hypercholesterolemia by inhibition of PCSK9 with alirocumab. J Am Coll Cardiol. 2014;64(21):2299-300. doi:10.1016/j.jacc.2014.07. 995.

51. Kassim SH, Li H, Bell P, Somanathan S, Lagor W, Jacobs F, et al. Adeno-associated virus serotype 8 gene therapy leads to significant lowering of plasma cholesterol levels in humanized mouse models of homozygous and heterozygous familial hypercholesterolemia. Hum Gene Ther. 2013;24(1):19-26. doi:10. 1089/hum.2012.108. 